\title{
Influence of Waste Marble Dust on the Improvement of Expansive Clay Soils
}

\author{
Hassan A. M. Abdelkader, ${ }^{1,2}$ Mohamed M. A. Hussein $\mathbb{D D}^{3}$ and Haiwang Ye $\mathbb{D}^{1}$ \\ ${ }^{1}$ School of Resources and Environmental Engineering, Wuhan University of Technology, Wuhan 430070, China \\ ${ }^{2}$ Mining and Petroleum Department, Faculty of Engineering, Al-Azhar University, Qena, Egypt \\ ${ }^{3}$ Civil Engineering Department, Faculty of Engineering, Sohag University, Sohag, Egypt
}

Correspondence should be addressed to Haiwang Ye; yehaiwang369@hotmail.com

Received 9 June 2021; Revised 7 August 2021; Accepted 8 September 2021; Published 22 September 2021

Academic Editor: Francesco Colangelo

Copyright (c) 2021 Hassan A. M. Abdelkader et al. This is an open access article distributed under the Creative Commons Attribution License, which permits unrestricted use, distribution, and reproduction in any medium, provided the original work is properly cited.

\begin{abstract}
The marble process industry from Shaq Al-Thouban region, which is located in East Cairo, Egypt, produces a huge amount of marble wastes every day during the cutting and processing stages. Up to now, most of these wastes are dumping on open land which creates serious environmental problems. The amount of waste marble from the processing stage is about 20 to $25 \%$ of the total processed stone. Egypt also suffers from the problem of expansive soil that occupies a large area of its lands, especially in the new cities that are built on these lands. The primary purpose of this study is to use this waste material in the soil stabilization in point of view utilization of this waste as local low-cost materials and elimination of their negative environmental impacts. The waste marble dust was mixed with expansive soil samples with various percentages of $5 \%, 10 \%, 15 \%, 20 \%$, and $25 \%$ by dry weight of soil. Different tests including Atterberg's limits, standard Proctor compaction, unconfined compressive strength (UCS), California bearing ratio (CBR), swelling percentage, linear shrinkage (LS) tests, and XRF and XRD analyses were conducted for natural and marble dust stabilized soils. The soil mixtures used for UCS, CBR, and swell tests were compacted at the optimum moisture content (OMC) and maximum dry density (MDD) using the standard Proctor compaction method and cured for 7 days. The results of the tests showed that there are significant effects in enhancing the properties of expansive soils. Also, the results showed that as the percentage of the marble dust increases the plasticity index, the swelling potential of the expansive clayey soil decreases. Furthermore, the optimum moisture content decreases, and the maximum dry density increases. Also, UCS, CBR, and the calcite content of the soil mixtures increase with the increase in marble dust content.
\end{abstract}

\section{Introduction}

Expansive soils are those that have major volume changes accompanied by changes in water contents. It swells when water is added and shrinks when it is evaporated. The swelling behavior is due to the presence of highly reactive clay minerals such as montmorillonite and smectite. These changes, swelling and shrinkage, in soil volume can cause light structures built on this soil to move unequally and crack. Problems of expansive soil have appeared as cracking and break-up of light building foundations, pavements, roadways, slab-on-grade members, channel linings, irrigation systems, gas pipelines, water pipelines, and sewer lines. The previous research estimated the cost of damage because this soil is more than twice the damage from floods, hurricanes, tornadoes, and earthquakes combined [1, 2].

The wastes which are solid in nature and remain at the place of their removal are called solid wastes. They may be classified into four groups based on the source of their production: (i) industrial solid wastes (fly ash, cement kiln dust, silica fume, copper slag, red mud, phosphogypsum, granulated blast furnace slag, ceramic dust, brick dust, and polyvinyl waste), (ii) domestic solid wastes (incinerator ash, waste tire, waste construction and demolition materials, eggshell powder, grain storage dust, and glass cullet), (iii) agricultural solid wastes (rice husk, bagasse ash, ground nutshell, olive cake residue, and wheat husk), and (iv) mineral solid wastes (quarry dust, marble dust, baryte 
powder, pyroclastic dust, limestone dust, granite dust, and mine tailings). Leaving the waste materials to the environment directly can cause environmental harm. Hence, recycling waste materials into sustainable civil engineering applications is of universal importance, as new ways to keep the natural resources and reducing the amount of waste materials being sent to landfills are sought globally. Recycling waste has become a research topic to eliminate its negative effects on the environment and its contribution to the economy. Also, recycling of waste keeps this material from being dumped into landfills and consuming landfill space. Many countries are functioning on the way to recycle and reuse solid wastes in applied science applications, like the assembly of concrete mix and therefore the manufacture of bricks, decorative plastic coating, ceramic tiles, cement, activated carbonate, lime, hollow blocks, wall tiles, and filler materials for embankments [3-7]. Stabilization using solid wastes is one of the different techniques to improve the engineering properties of problematic soils to make them suitable for construction [8-24].

Expansive soils occupy large areas of Egyptian lands, and due to the large population increase, the Egyptian government was forced to establish new cities on these lands. Major engineering problems have appeared in the constructions built on it. So, it was necessary to focus on finding suitable methods to improve the properties of this soil using the local waste material. Nature has gifted Egypt with huge deposits of high-quality marble and granite. Egypt produces over 50 different types of marble and granite with an annual production of about 3.5 million tons. So, it ranks as the fifth producer and the seventh exporter of marble and granite in the world. Quarries and factories for marble and granite are found in different places in Egypt as shown in Figure 1 [25].

Shaq El-Thouban region in Katameyya is considered the largest industrial gathering in Egypt for processing marble and granite. It has the maximum concentration of marble and granite factories in Egypt reaching around 400 factories. This area was occupied by quarry workers quarrying the limestone within the hills and mountains of Katameyya at the beginning. Along time, interested investors in this area were granted about $10,000 \mathrm{~m}^{2}$ for the value of $\$ 12$ per $\mathrm{m}^{2}$ to build their stone factories. Quarrymen who began to add the limestone hills switched their stone factories to figure in marble and granite which proved more profitable. In Shaq Al-Thouban, a major quantity of stone slurry is generated from the processing of stones. Generally, it is forbidden to discharge this slurry in the public sanitary system because of its highly alkaline nature. So, the slurry is stored in basins and the settled sludge is collected and disposed of near the factories. After drying, the collected powder heaps become airborne, causing air pollution and water contamination, in addition to increasing soil alkalinity and reducing its richness and plant productivity. The high $\mathrm{pH}$ of the dry slurry makes it harmful to the lungs and eyes [26].

The marble stones industry is one of the greatest promising business areas of the mining sector in Egypt. This industry is increasing gradually due to the increasingly greater demand for the Egyptian stones, whether on the local or the international scale which led to a progressive

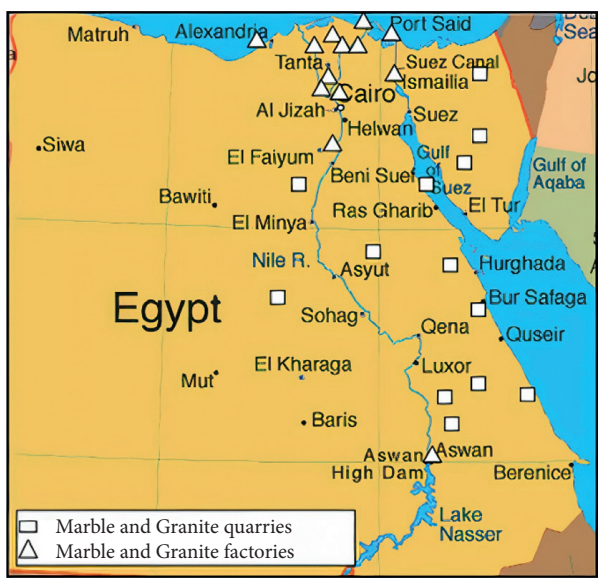

FIgURE 1: Location of marble, granite quarries, and factories in Egypt [25].

production rate more than ever before. This waste can be classified into two groups that are mining or quarrying waste and processing waste. About $50 \%$ of the mined marble becomes waste during the process of mining to finishing marble. Usually, these wastes are found in the form of boulders, grits, fines, and slurry. The amount of wastes from the cutting and sawing process can easily reach 20 to $25 \%$ of the total volume of the block. These wastes need a large area of land to be disposed of [4].

In recent years, some efforts have been undertaken to consider the possibilities of reusing marble and granite powders for soil stabilization. The marble dust powder has a huge amount of lime content and had been suggested by numerous researchers for expansive soil improvement. Several studies [27-36] examined the enhancement of expansive soils by the addition of marble dust in different percentages. They showed the advantageous uses of marble dust alone or in combination with chemicals and waste stabilizers such as lime, cement, and fly ash to improve the various properties of expansive soils. Additionally, the coarser particles and the major shear strength due to the high internal friction of marble dust are useful for improving the workability, plasticity, and strength of expansive soil.

Singh and Yadav [37] have examined the effect of marble dust added with various percentages from $0 \%$ to $10 \%$ by weight of dry soil. The test results indicated a big variation in consistency limits of samples containing marble dust. The liquid limit decreased from $67.49 \%$ to $52.01 \%$. The plasticity index decreased from $37.16 \%$ to $10.43 \%$. Also, the differential free swell decreased from $60 \%$ to $14 \%$, showing a considerable decrease in swelling behavior. Sabat and Nanda [38] studied the effect of marble powder with rice husk ash on expansive soil. The results indicated that by the addition of marble powder and rice husk to the soil, the California bearing ratio and unconfined compression strength values increase. Saygll [39] indicated that marble dust addition enhances the shear strength parameters and reduced the swell potential of the expansive soil. Moreover, marble dust had a noticeable role in the hydration process because of its high calcium content. Also, marble dust addition to the clay 
samples will decrease the cost of constructing structures on problematic soils and finding new utilization areas for waste marble dust which will diminish the environmental pollution. Besides, using waste marble dust in problematic soils will have a great role in the economy and keeping the resources. Sivrikaya et al. [40] studied the effect of calcite marble powder (CMP) and dolomitic marble powder (DMP) on the geotechnical properties of cohesive soils. Atterberg limits, linear shrinkage, expansion index, and one-dimensional consolidation tests were executed on untreated and treated samples with 5, 10, 20, 30, and 50\% of waste CMP and DMP. The laboratory test results indicated that the waste marble powders were effective in soil stabilization by reducing the plasticity index from 49 to $26 \%$ and from 21 to $9 \%$ for the high-plasticity clay $(\mathrm{CH})$ and the high-plasticity silt (MH) samples, respectively, and also, expansion index from 45 to 20 and from 32 to 7 for $\mathrm{CH}$ and $\mathrm{MH}$ samples, respectively, swelling index from 0.0030 to 0.0012 and from 0.013 to 0.010 for $\mathrm{CH}$ and $\mathrm{MH}$ samples, respectively, compression index from 0.013 to 0.010 and from 16.2 to 10.5 for $\mathrm{CH}$ and $\mathrm{MH}$ samples, respectively, and linear shrinkage from 16.2 to $10.5 \%$ for the $\mathrm{CH}$ sample. Jain et al. [41] investigated the influence of marble dust for improving the geotechnical behavior of expansive soil. Comprehensive geotechnical tests (consistency limits, free swell index, compaction characteristics, one-dimensional consolidation tests, and unconfined compressive strength) have been carried out using a wide range of marble dust contents up to $80 \%$ to adjust the content of marble dust for soil stabilization and to understand its interactive behavior with soil. The main results indicated that marble dust can be utilized effectively to enhance soil plasticity and to control the swell behavior. The results showed that marble dust accelerates the strength of soil at early curing periods and that the optimum improvement in the strength behavior of the soil is gained with a marble dust content of $20 \%$. Also, it is concluded that the production of a cheap and more strong soil layer by using these wastes can help the civil engineer to ensure the economy in the infrastructure project and address environmental degradation.

From the literature review, it has been observed that limited studies have been carried out using marble dust in the improvement of expansive soil properties although there is a large amount from this material and large areas have expansive soils in the world. This study highlights the practicality of using local marble waste dust and mixing it with expansive soil to achieve the economy and preserve the environment. To achieve this objective, a laboratory study was carried out to examine the impacts of local marble waste dust on the improvement of expansive soil properties. The behavior of this expansive soil amended with marble dust is inspected in terms of Atterberg's limits, standard Proctor compaction, unconfined compressive strength, California bearing ratio, swelling percentage, linear shrinkage tests, and chemical and mineralogical analysis by X-ray fluorescence (XRF) and $\mathrm{X}$-ray diffractometer (XRD) at different percentages of marble dust.

\section{Materials}

The materials used in this study are expansive soil and marble dust.

2.1. Expansive Soil. The expansive soil (ECS) sample was collected from the village El-Salheya, Qena city, Egypt (latitude $26^{\circ} 08^{\prime} 18^{\prime \prime} \mathrm{N}$ and longitude $32^{\circ} 49^{\prime} 10^{\prime \prime} \mathrm{E}$ ). The soil sample was collected at $1.5 \mathrm{~m}$ depth from the ground level. The disturbed soil was excavated, kept in polythene bags, and transported to the laboratory for experiments. The average geotechnical properties of the soil are shown in Table 1 . Based on the liquid limit and the plasticity index, and according to Holtz and Gibbs [42], Chen [43], and IS 1498 [44], the soil can be classified as medium expansive. The particle size distribution for untreated expansive soil is shown in Figure 2.

2.2. Marble Dust. The used marble dust (MD) was taken from the "Shaq Al-Thouban" region which is located in south Cairo, Egypt, as a by-product from the cutting and the processing industry. Figure 3 shows the different shapes of MD resulted from the stone factories in the Shaq AlThouban region. The specific gravity of the marble dust was found to be 2.76 . The marble dust was prepared by drying in an oven for 24 hours at the temperature of $105^{\circ} \mathrm{C}$ to remove moisture and then pulverized repeatedly using a plastic hammer before being used to remove any agglomeration from powder. Particle size distribution analysis showed that the used marble dust consists of $12 \%$ clay, $35 \%$ silt, and $53 \%$ sand. The particle size distribution for marble dust is shown in Figure 2. The chemical components of the expansive soil and marble dust were analyzed according to XRF tests. Table 2 shows that the expansive soil has silicon dioxide as the major component with minor contents of $\mathrm{Al}_{2} \mathrm{O}_{3}$ and $\mathrm{Fe}_{2} \mathrm{O}_{3}$, indicating its siliceous nature. On the other hand, $\mathrm{MD}$ consists mainly of calcium oxide with minor contents of $\mathrm{SiO}_{2}$, indicating its carbonate nature. By using X-ray diffraction, it is shown that the soil consists of quartz and montmorillonite as a major mineral constitute, while the main components of marble powder are calcite minerals as shown in Figure 4.

\section{Testing Methods}

Marble dust was mixed with the expansive soil by different proportions $(5 \%, 10 \%, 15 \%, 20 \%$, and $25 \%)$ by the dry weight of the soil. To achieve the objectives of this study, a series of laboratory tests were conducted on untreated (UECS) and treated expansive soil (TECS) by performing the sieve analysis, in accordance with ASTM D6913, 2017, Atterberg's limits, in accordance with ASTM D4318-10e1, 2010, compaction characteristics (maximum dry density and optimum moisture content), in accordance with ASTM D698, 2003, unconfined compressive strength (UCS), in accordance with ASTM D2166, 2003, California bearing ratio (CBR), in accordance with ASTM D 1883, one-dimensional swell tests, in accordance with ASTM D4546, 
TABle 1: Average geotechnical properties of used ECS.

\begin{tabular}{lc}
\hline Test & Value \\
\hline Liquid limit (\%) & 42.12 \\
Plastic limit (\%) & 25 \\
Plasticity index (\%) & 17.12 \\
Linear shrinkage (\%) & 10.7 \\
Free swell (\%) & 95 \\
Specific gravity & 2.68 \\
Sand (4.75-0.075 mm) (\%) & 2.12 \\
Silt (0.075-0.005 mm) (\%) & 71.85 \\
Clay (<0.005 mm) (\%) & 26.03 \\
Type of soil (USCS) & CI \\
\hline
\end{tabular}

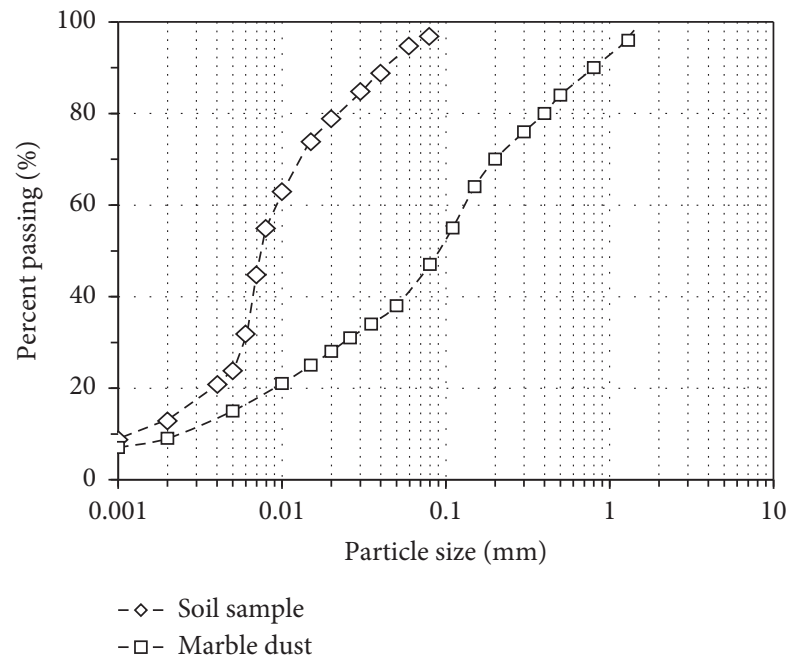

FIGURe 2: Grain size distribution curves for the soil sample and MD.

2003, and linear shrinkage (LS), in accordance with BS 1377$2: 90,1990$. Samples for different tests were remolded at their maximum dry density and optimum moisture content. Moreover, a chemical and mineralogical analysis was performed to investigate the reaction products of the stabilized soil.

\section{Results and Discussions}

4.1. Effect of MD on Atterberg's Limits. To illustrate the effect of MD content on the plasticity characteristics of ECS, values of Atterberg's limits (liquid limit (LL), plastic limit (PL), and plasticity index (PI)) were determined. The test results for UECS and TECS are presented in Figure 5. It can be seen that the addition of MD has a significant effect on Atterberg's limits of the expansive soil. Liquid limit, plastic limit, and plasticity index decrease with the increase of MD percentages. The liquid limit decreases from $42.12 \%$ to $29.5 \%$, the plastic limit decreases from $25 \%$ to $18.8 \%$, and the plasticity index decreases from $17.12 \%$ to $10.7 \%$ with increasing the adding marble dust from $0 \%$ to $25 \%$, respectively. Also, it is obvious that the rate of decrease for Atterberg's limits is more until reaching the adding percentage from MD to $15 \%$; after that, the rate is small. A significant reduction in liquid limit indicates the expected reduction in the degree of the potential expansiveness of the TECS. This is attributed to the nonplastic nature of the marble dust particles. This result complies with the results of previous studies $[17,20,30,40,41]$.

A regression model has been established to predict Atterberg's limits of the expansive soil stabilized with different percentages of MD. The models are

$$
\begin{aligned}
\mathrm{LL}_{t} & =0.0115 \mathrm{MD}^{2}-0.8024 \mathrm{MD}+\mathrm{LL}_{U} \\
R^{2} & =0.997 \\
\mathrm{PL}_{t} & =0.0043 \mathrm{MD}^{2}-0.0 .3614 \mathrm{MD}+\mathrm{PL}_{U} \\
R^{2} & =0.998 \\
\mathrm{LL}_{t} & =0.0072 \mathrm{MD}^{2}-0.4409 \mathrm{MD}+\mathrm{LL}_{U} \\
R^{2} & =0.994
\end{aligned}
$$

where $\mathrm{LL}_{T}$ and $\mathrm{LL}_{U}$ are the liquid limit of treated and untreated expansive soil (\%), respectively, $\mathrm{PL}_{T}$ and $\mathrm{PL}_{U}$ are the plastic limits of treated and treated expansive soil (\%), respectively, $\mathrm{PI}_{T}$ and $\mathrm{PI}_{U}$ are the plasticity index of treated and untreated expansive soil (\%), respectively, MD is the percentage of marble dust (\%), and $R^{2}$ is the coefficient of determination.

Figure 6 shows the positions of the virgin expansive soil and MD stabilized expansive soil in the plasticity chart. It is clear that, with the increase of MD percentage, the soil changes from CI (inorganic clay of medium plasticity) to $\mathrm{CL}$ (inorganic clay of low plasticity) as per the unified soil classification system. This has happened due to the replacement of fine-grained particles of expansive soil with coarse-grained particles of MD. Also, the expansive soil changes from medium to low expansive. This result is compatible with that of a study performed by [40].

\subsection{Effect of $M D$ on the Compaction Characteristics.} Standard compaction tests were carried out on UECS and TECS. The results of these tests are shown in Figure 7. It can be noticed that the addition of MD led to shifting the compaction curves to the left and above the compaction curve of UECS.

Figure 8 shows the variation of maximum dry density (MDD) with the percentage of MD. It can be seen that with the increase in the percentage of $\mathrm{MD}$, the MDD of soil goes on increasing. The MDD increases from $18.42 \mathrm{kN} / \mathrm{m}^{3}$ to $20.2 \mathrm{kN} / \mathrm{m}^{3}$ when MD is increased from 0 to $25 \%$. The reason behind the increase of MDD is due to the occupation of the void spaces of waste marble dust by the clay soil particles and the cementitious effect of $\mathrm{CaO}$ present in the $\mathrm{MD}$ and also the replacement of MD particles having high specific gravity with soil particles having a low specific gravity of mixes. Further, the significant improvement in the particle size distribution of ECS (i.e., predominated with clay-sized particles) with the addition of MD (i.e., predominated with sand-sized particles) results in improving the resistance against compaction effort and thereby increases in MDD [41]. However, Okagbue and Onyeobi [45] concluded that 


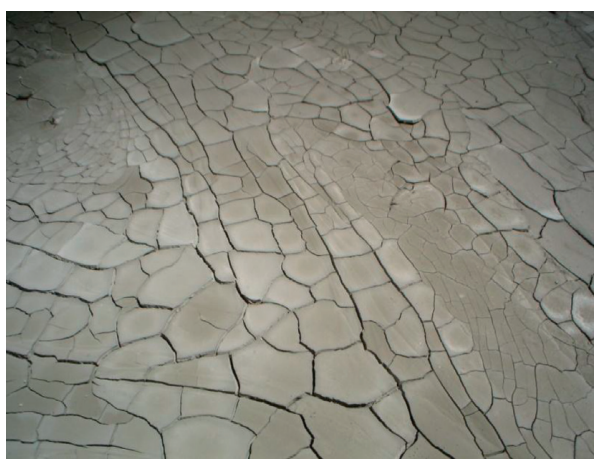

(a)

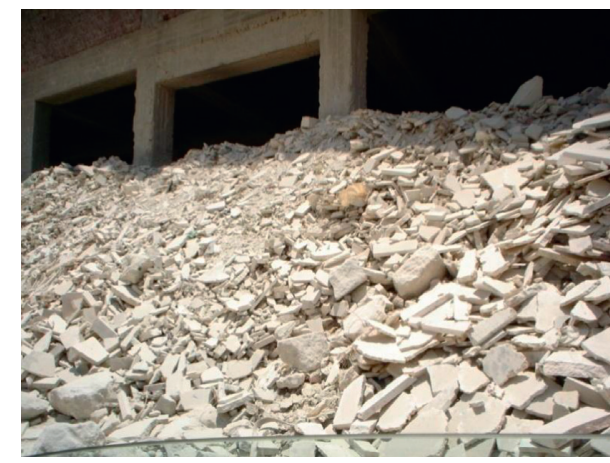

(b)

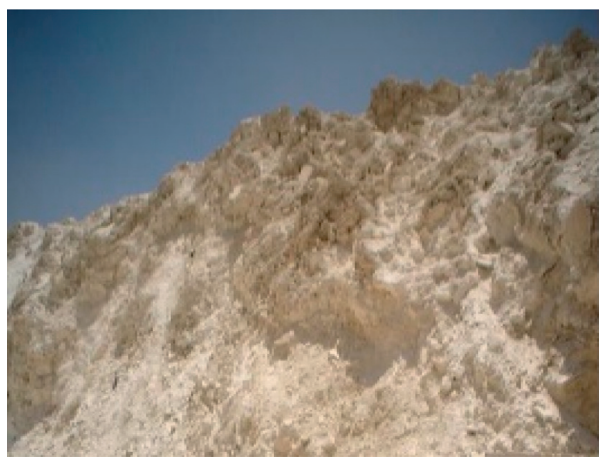

(c)

Figure 3: Different shapes of marble wastes resulted from marble factories in the Shaq Al-Thouban region. (a) Slurry state. (b) Solid State. (c) Dust state.

TABLE 2: Chemical analysis of the expansive soil and marble dust.

\begin{tabular}{lcccccccccc}
\hline Parameter & $\mathrm{SiO}_{2}$ & $\mathrm{Al}_{2} \mathrm{O}_{3}$ & $\mathrm{Fe}_{2} \mathrm{O}_{3}$ & $\mathrm{CaO}$ & $\mathrm{MgO}$ & $\mathrm{K}_{2} \mathrm{O}$ & $\mathrm{TiO}_{2}$ & $\mathrm{SO}_{3}$ & $\mathrm{MnO}$ & $\mathrm{LOI}$ \\
\hline Expansive soil & 49.47 & 12.85 & 11.94 & 5.79 & 2.10 & 1.61 & 2.98 & 4.29 & 0.33 & 8.64 \\
Marble dust & 3.96 & 0.51 & 1.19 & 72.26 & 0.27 & 0.08 & 0.17 & - & - & 21.56 \\
\hline
\end{tabular}

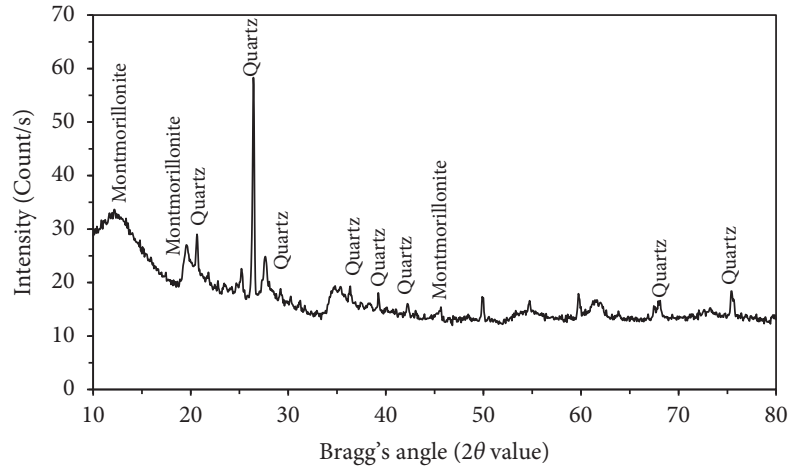

(a)

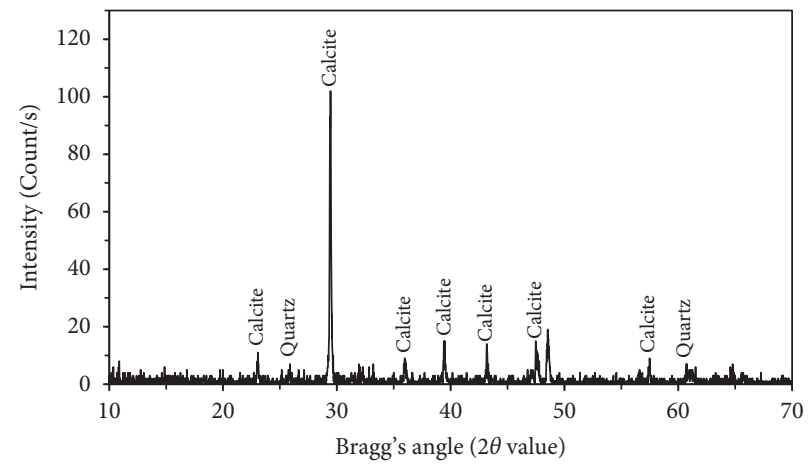

(b)

Figure 4: Mineralogical composition. (a) Expansive soil. (b) Marble dust.

the increase in MDD of mixed soil with MD is due to the pozzolanic reaction and formation of lime-like product $[\mathrm{Ca}$ $\left.(\mathrm{OH})_{2}\right]$ which dissociates into $\mathrm{Ca}^{2+}$ and $\mathrm{OH}^{-}$ions. This phenomenon is validated by the existence of silica and alumina in the soils and calcium oxide in marble dust. A regression model has been established to predict the MDD of the expansive soil stabilized with different percentages of MD. The model is 


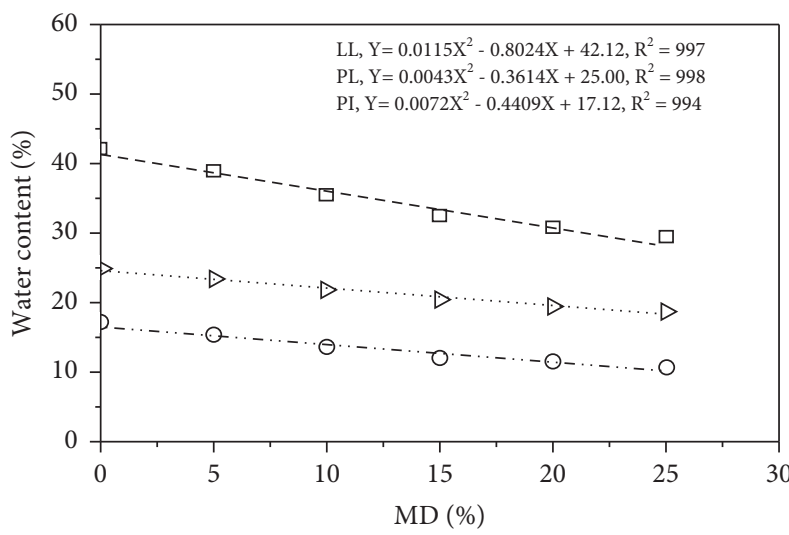
$\square$ Liquid limit, measured
- - - Liquid limit, fitted
$\triangleright$ Plastic limit, measured Plastic limit, fitted
○ Plasticity index, measured Plasticity index, fitted

FIgURE 5: Variation of Atterberg's limits with different percentages of MD.

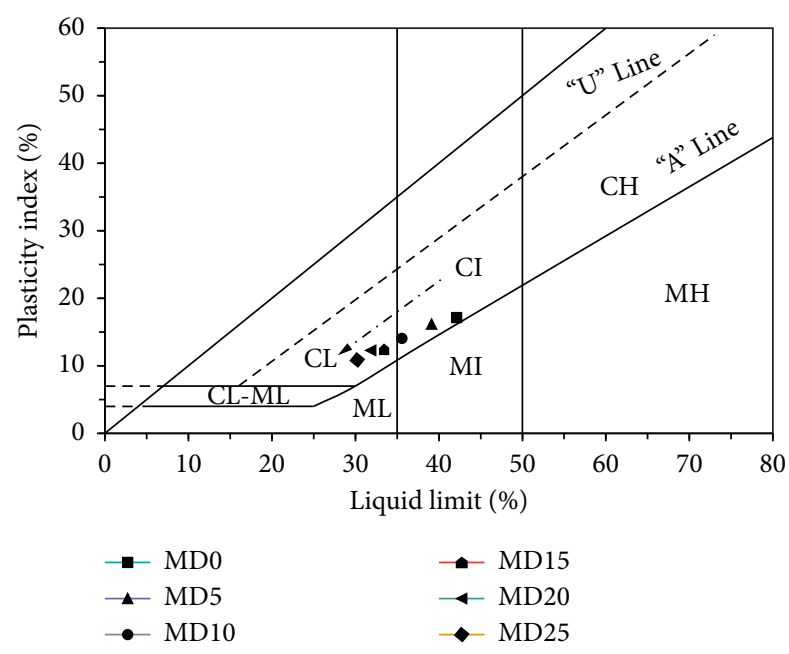

FIgure 6: Positions of UECS and TECS on the plasticity chart.

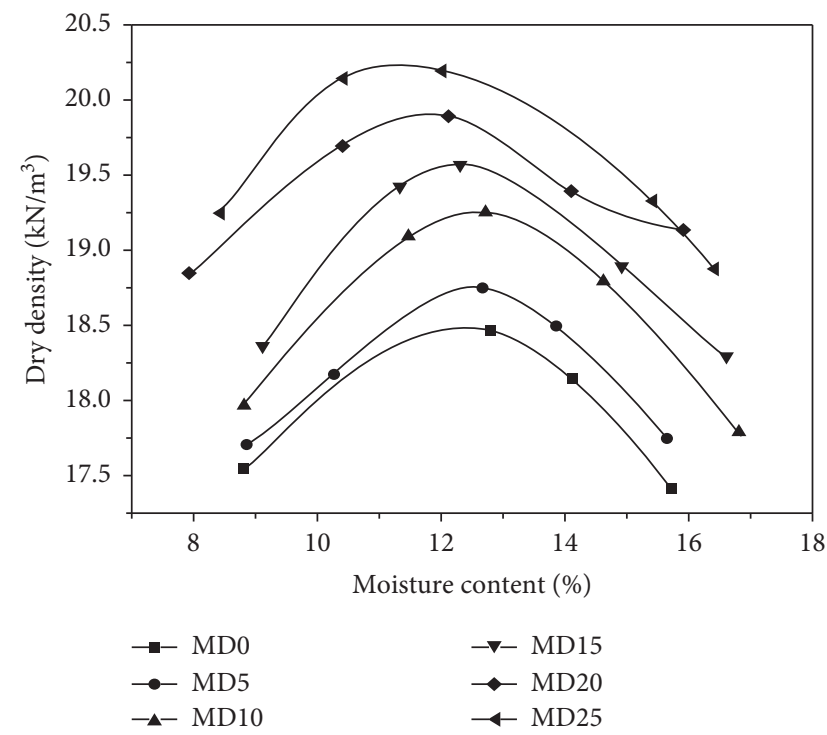

FIgURE 7: Relation between dry density and moisture content for UECS and TECS. 


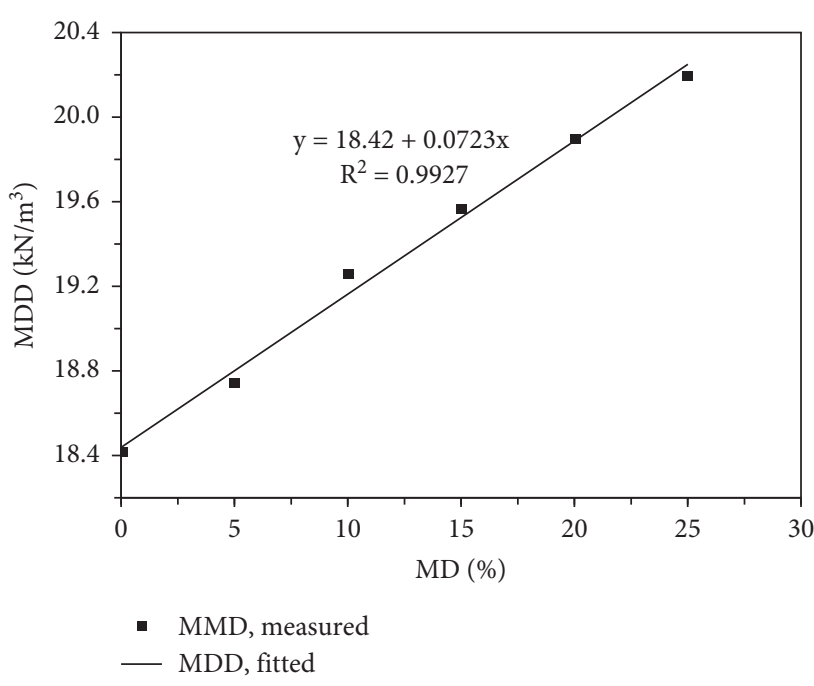

Figure 8: Variation of MDD with the percentage of MD.

$$
\mathrm{MDD}_{T}=0.0723 \mathrm{MD}+\mathrm{MDD}_{U}, R^{2}=0.9927
$$

where $\mathrm{MDD}_{T}$ and $\mathrm{MDD}_{U}$ are the maximum dry density of treated and untreated expansive soil $\left(\mathrm{kN} / \mathrm{m}^{3}\right)$, respectively.

Figure 9 shows the variation optimum moisture content (OMC) with the percentage of MD. It was found that, with the increase in the percentage of $\mathrm{MD}$, the $\mathrm{OMC}$ of soil goes on decreasing. The OMC decreases from $13.1 \%$ to $11.2 \%$ when $\mathrm{MD}$ is increased from 0 to $25 \%$, respectively. The reason for such behavior is due to the replacement of soil particles (fine particles) with MD particles (coarser particles) and thus increases the coarser particles in the mix, leading to the decrease of total surface activity and therefore lesser water-adsorptive capacity. A regression model has been established to predict the OMC of the expansive soil stabilized with different percentages of MD. The model is

$$
\begin{aligned}
\mathrm{OMC}_{T} & =0.0777 \mathrm{MD}-\mathrm{OMC}, \\
R^{2} & =0.9884,
\end{aligned}
$$

where $\mathrm{OMC}_{T}$ and $\mathrm{OMC}_{U}$ are the optimum moisture content of treated and untreated expansive soil (\%), respectively.

It can be summarized that the compaction characteristics of ECS are influenced expressively by the addition of MD. Similar behaviors of compaction characteristics have been described by several previous researchers for ECS amended with MD [20, 27, 32, 40, 41].

\subsection{Effect of MD on Unconfined Compressive Strength.} The unconfined compressive tests were carried out on an untreated expansive soil specimen and five treated expansive soil specimens mixed with the various percentages of $\mathrm{MD}$ at their MDD and OMC for 7 days of curing time. This curing time was selected due to previous research showing that increasing the curing time to more than 7 days does not have a significant effect in increasing TECS strength [31, 41]. The results of tests in the form of unconfined compressive

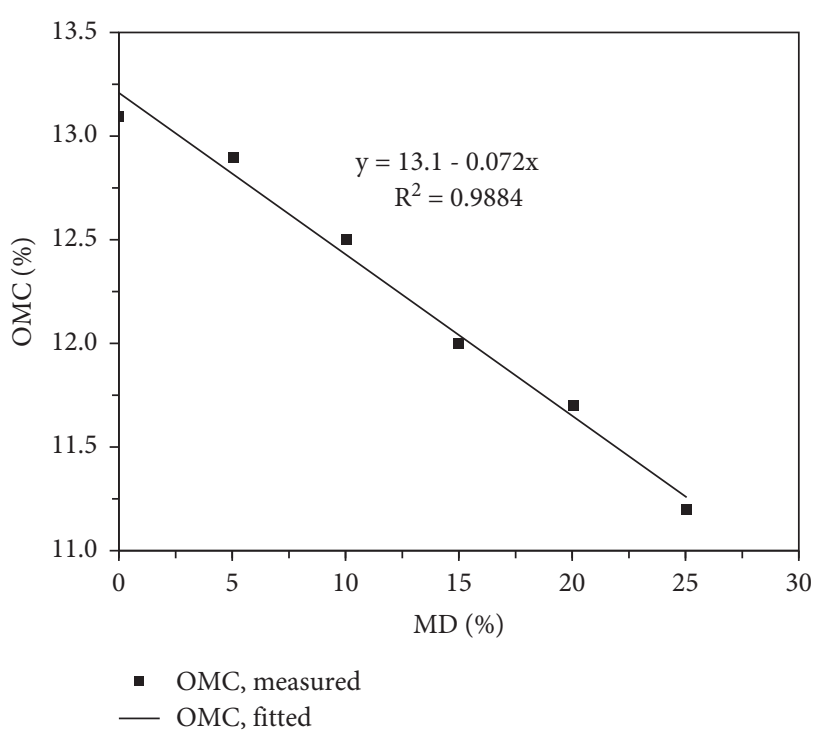

Figure 9: Variation of OMC with the percentage of MD.

strength versus strain are presented in Figure 10. From this figure, it can be seen that with an increase in the percentage of MD, the UCS of soil goes on increasing. The UCS increases from $417 \mathrm{kPa}$ to $600 \mathrm{kPa}$ when MD is increased up to $25 \%$; i.e., the UCS value of TECS is 1.44 times as compared to UECS. On the other hand, failure strain indicates a decreasing trend with the increment of MD content. This is evidence of higher stiffness. The increase in the strength of MD stabilized expansive soil may be attributed to the improvement in the gradation, and the increase in the compactness of the soil matrix is due to the decrease in porosity and the enhancement in the interparticle bonding between the soil and MD. In addition, the pore-filling effect of fine powder. As already discussed, this powder is an inert addition and could be assumed as ultrafine aggregates filling voids.

Figure 11 displays the relation between the UCS and the adding percentages of MD to the expansive soil. It can be seen that there is a linear trend of increase in the value of the UCS as the MD increases for all treated samples under the 7 curing periods. Also, the rate of increase is more up to $20 \%$ MD; after that, the rate is low. Similar improvement in UCS of expansive soil stabilized with MD was reported by Jalal et al. [32], where an experimental study was performed using different percentages $(0 \%, 2 \%, 4 \%, 6 \%, 8 \%$, and $10 \%)$ from marble industry waste (MIW) to stabilize expansive soil. The results indicated that MIW is an efficacious additive for enhancing the unconfined compressive strength of tested clay soils, and the optimum MIW content can be observed as $10 \%$. They attributed this to soil-lime reaction, and an increase of $300 \%$ and $154 \%$ in the unconfined strength is recorded at 3 days and 7 days, respectively. On the other hand, Jain et al. [41] investigated the effect of MD on stabilization of expansive soils using a wide range of $\mathrm{MD}$ contents $0 \%, 5 \%, 10 \%, 15 \%, 20 \%, 25 \%, 40 \%, 60 \%$, and $80 \%$. The results revealed that the strength of the soil increases continuously with an increase in MD content up to $20 \%$, regardless of the curing period. A further increase in the MD 


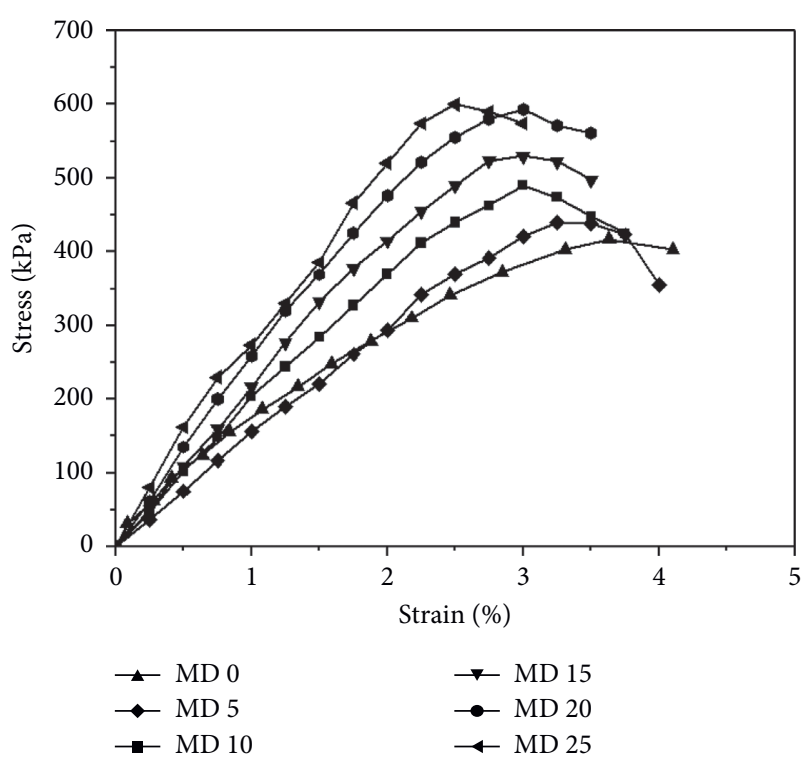

FIgURE 10: Stress-strain curves at different percentages of MD.

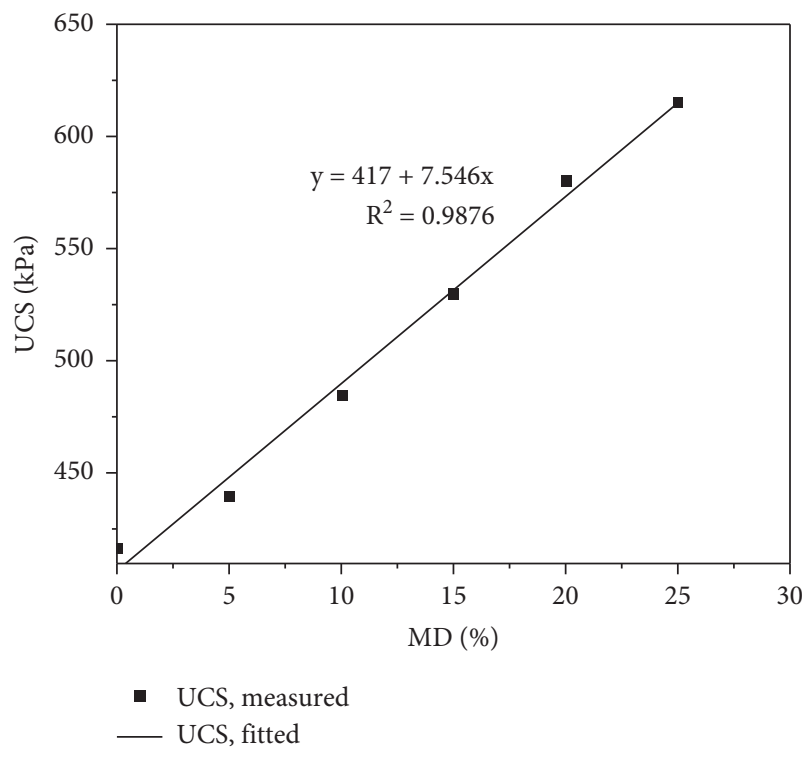

FIGURE 11: Variation of UCS with the percentage of MD.

content leads to lower strength of the soil. However, it is interesting to note that the strength of the soil is constantly enhanced with an increase in the curing period at any MD content. Hence, a marble dust content of $20 \%$ can be considered as the optimum MD content from the viewpoint of strength in terms of amending the soil. Choksi et al. [46] conducted expansive soil stabilization utilizing waste marble powder in dosages of $10 \%, 20 \%, 30 \%, 40 \%, 45 \%$, and $50 \%$ by weight of soil. The results revealed that there is a significant increase in UCS with an increase of the dosage of MD, and this increase reaches the maximum at $45 \%$ of $\mathrm{MD}$, and after that, it decreases. It can be concluded from the results of this study and the results obtained from previous studies that UCS of expansive soil generally increases with the increase of adding MD. However, the optimum content of MD differs from one study to another, and these variations can be attributed to the different components of expansive soil and the MD from one place to another. A regression model has been established to predict the UCS of the expansive soil stabilized with different percentages of MD. The model is

$$
\begin{aligned}
\mathrm{UCS}_{T} & =7.546 \mathrm{MD}+\mathrm{UCS}_{U}, \\
R^{2} & =0.9876
\end{aligned}
$$

where $\mathrm{UCS}_{T}$ and $\mathrm{UCS}_{U}$ are the unconfined compressive strength of treated and untreated expansive soil $(\mathrm{kPa})$, respectively.

4.4. Effect of MD on California Bearing Ratio (CBR). The soaked CBR tests were performed on UECS and TECS with different percentages of MD at maximum dry density and optimum moisture content for 7 days of curing time. The results of the tests are presented in Figure 12. From this figure, it can be seen that, with increasing the content of $\mathrm{MD}$, the soaked CBR of soil goes on increasing. The soaked CBR increases from $6.19 \%$ to $12.9 \%$ when $\mathrm{MD}$ is increased up to $25 \%$. There is a $108 \%$ increase in soaked CBR of soil at this percentage of $\mathrm{MD}$ as compared with untreated soil. The improvement can be attributed to filling voids between expansive soil grains by MD and also improvement in gradation and thereby an increase in MDD of soil; consequently, CBR values were increased. Based on these results, it can be concluded that the expansive soil treated with MD performs better as a subgrade material, which requires a lower thickness of the base course compared with the untreated expansive soil. This behavior is generally compatible with previous studies [17, 27, 32, 41]. A regression model has been established to predict the CBR of the expansive soil stabilized with different percentages of MD. The model is

$$
\begin{aligned}
\mathrm{CBR}_{T} & =0.2313 \mathrm{MD}+\mathrm{CBR}_{U}, \\
R^{2} & =0.9895
\end{aligned}
$$

where $\mathrm{CBR}_{T}$ and $\mathrm{CBR}_{U}$ are the California bearing ratio of treated and untreated expansive soil (\%), respectively.

4.5. Effect of MD on Swelling Potential. One-dimensional swell percentage versus time graphs were obtained from one-dimensional swell tests on an untreated expansive soil specimen and five treated expansive soil specimens mixed with the various percentages of MD at their MDD and OMC for 7 days of curing time. The seating load specified by the standard is $6.9 \mathrm{kPa}$. The swell percentages with respect to the logarithm of time plots are depicted in Figure 13. It can be observed that the tested specimens swelled for 1440 minutes and then became constant. Also, there is a significant effect on the decrease of the axial swelling ratio of treated expansive soil with increasing MD percentages. When the soil reaches its maximum heave, the final heave was measured, and swelling potential $(S \%)$ was calculated according to the following equation: 


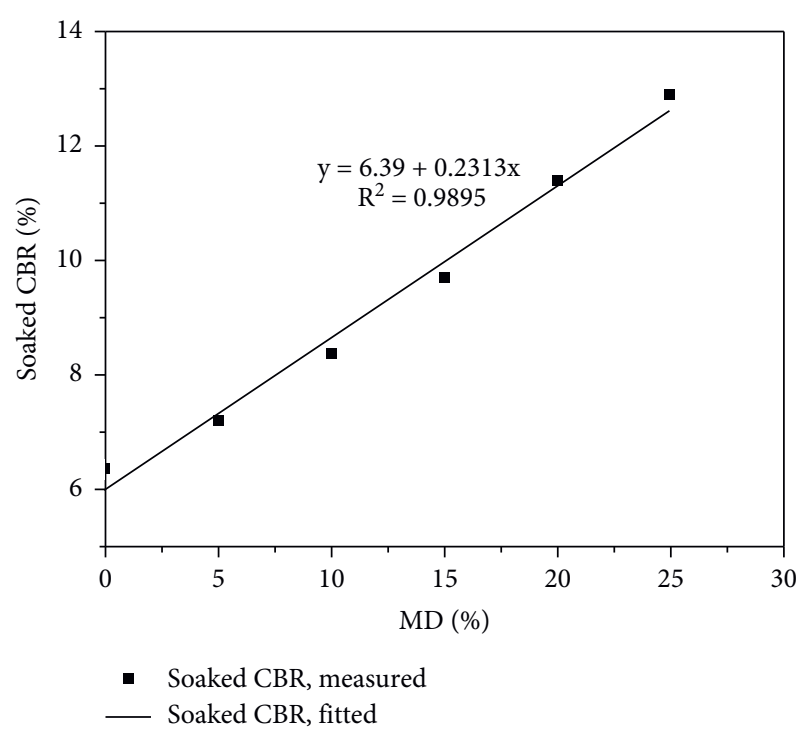

FIGURE 12: Variation of CBR with different percentages of MD.

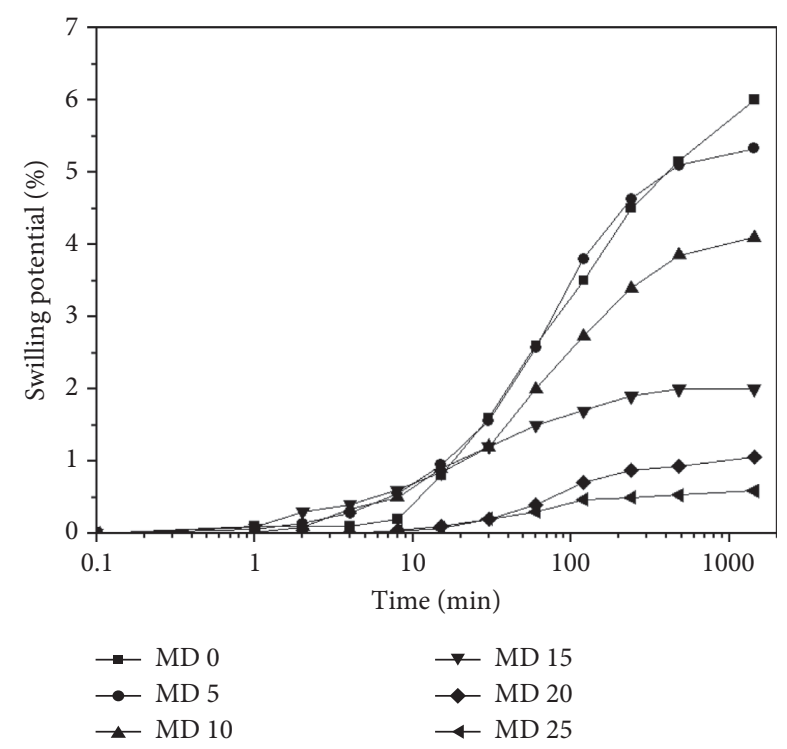

FIGURE 13: Axial swelling ratio versus time for different percentages of MD.

$$
S(\%)=\left[\frac{H_{P}-H_{o}}{H_{o}}\right] \times 100,
$$

where $H_{p}$ is the maximum height of the soil specimen at the end of the primary swell and $H_{o}$ is the initial height of the soil specimen.

Figure 14 depicts the variations of swilling potential with percentages of adding MD to the expansive soil up to $25 \%$. It can be seen clearly that as the percentage of MD increases, the swilling potential gradually decreases. This happened due to the replacement of the swelling particles of the soil with the nonswelling particles of MD that works as an inert material. The ratios of decrease were reported as $11.17 \%$, $31.67 \%, 66.67 \%, 76.67 \%$, and $91 \%$ with adding MD by $5 \%$,

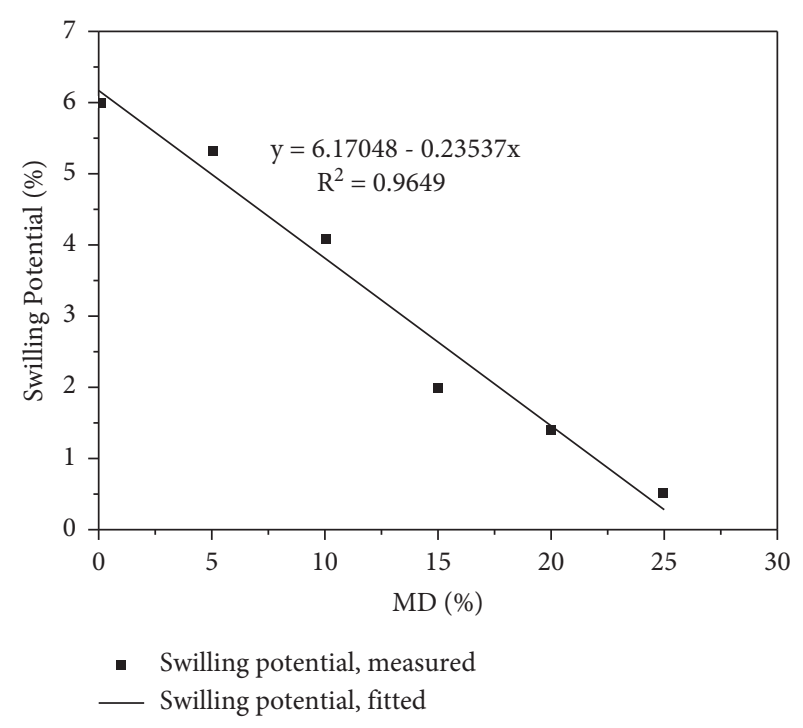

FIgURE 14: Variation of swelling potential with different percentages of MD.

$10 \%, 15 \%, 20 \%$, and $25 \%$, respectively. This observation agrees well with previous studies on the efficacy of marble dust utilization in reducing the swelling potential of expansive soil $[17,20,31,33,34,36,47]$. A regression model has been established to predict the swelling potential of the expansive soil stabilized with different percentages of MD. The model is

$$
\begin{aligned}
S_{T}(\%) & =-0.2354 \mathrm{MD}+\mathrm{SU} \\
R^{2} & =0.9649
\end{aligned}
$$

where $S_{\mathrm{T}}$ and $S_{\mathrm{U}}$ are the swelling potential of treated and untreated expansive soil (\%), respectively.

4.6. Effect of MD on Linear Shrinkage. Linear shrinkage (LS) tests were carried out to determine the one-dimensional shrinkage of stabilized expansive soils in terms of MD content. The test trough was filled with a stabilized soil specimen at the liquid limit. The trough with wet material was placed in a drying oven and dried at a temperature of $110 \pm 5^{\circ} \mathrm{C}$ for about $24 \mathrm{~h}$ until all shrinkage stopped. The length of the dry soil samples was measured with digital calipers, and the values of linear shrinkage were determined for the stabilized ECS samples. The results of the tests are presented in Figure 15. From this figure, it can be seen that the LS decreases drastically with increasing MD contents, where the linear shrinkage of the stabilized ECS samples was found to be decreased from $10.7 \%$ for UECS to $4.9 \%$ for TECS with $25 \% \mathrm{MD}$. Also, the linear shrinkage of the stabilized ECS samples was found to be decreased by $4.39 \%$, $20.37 \%, 35.79 \%, 45.79 \%$, and $54.21 \%$ with adding MD by $5 \%$, $10 \%, 15 \%, 20 \%$, and $25 \%$ to expansive soil, respectively. These results are consistent with the previous studies $[35,40]$. A regression model has been established to predict the LS of the expansive soil stabilized with different percentages of $\mathrm{MD}$. The model is $\mathrm{LS}_{T}=-0.2361 \mathrm{MD}+\mathrm{LS}_{U}$, 


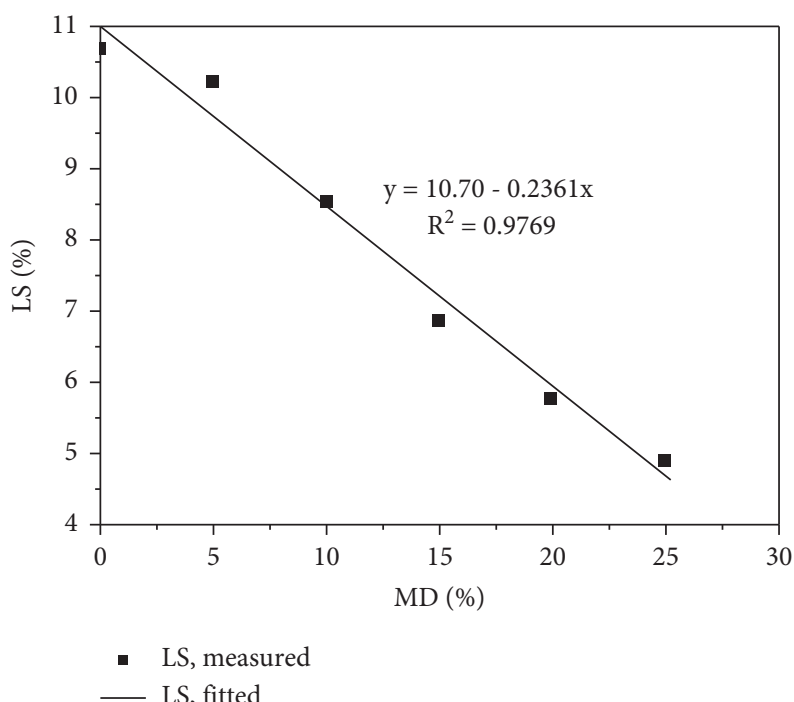

FIGURE 15: Results of linear shrinkage tests.

TABLE 3: Chemical composition of MD, raw soil, and raw soil-MD mixes, as determined from XRF.

\begin{tabular}{|c|c|c|c|c|c|c|c|}
\hline Symbol & $\mathrm{MD}$ & MD0 & MD5 & MD10 & MD15 & MD20 & MD25 \\
\hline $\mathrm{SiO}_{2}$ & 3.96 & 49.47 & 48.3 & 45.9 & 44 & 42 & 39 \\
\hline $\mathrm{AL}_{2} \mathrm{O}_{3}$ & 0.51 & 12.85 & 12.5 & 12.3 & 11 & 10.8 & 10.3 \\
\hline $\mathrm{Fe}_{2} \mathrm{O}_{3}$ & 1.19 & 11.94 & 7.6 & 8.4 & 8.6 & 8.4 & 9 \\
\hline $\mathrm{CaO}$ & 72.26 & 5.79 & 8.2 & 8.8 & 9.1 & 9.6 & 11 \\
\hline $\mathrm{MgO}$ & 0.27 & 2.1 & 2.6 & 2.1 & 1.6 & 2.9 & 2.6 \\
\hline $\mathrm{K}_{2} \mathrm{O}$ & 0.08 & 1.61 & 1.2 & 1.3 & 1.2 & 1.3 & 1.3 \\
\hline $\mathrm{TiO}_{2}$ & - & 2.98 & 2.4 & 1.6 & 2.7 & 1.8 & 2.6 \\
\hline $\mathrm{SrO}$ & - & - & 2.1 & 2.4 & 2.7 & 2.2 & 2 \\
\hline $\mathrm{SO}_{3}$ & 0.17 & 4.29 & 4.2 & 3.5 & 3.8 & 3.3 & 3.1 \\
\hline $\mathrm{MnO}$ & - & 0.33 & 0.3 & 0.3 & 0.22 & 0.28 & 0.3 \\
\hline LOI & 21.56 & 8.64 & 10.6 & 13.4 & 15.08 & 17.42 & 18.8 \\
\hline
\end{tabular}

$$
\begin{aligned}
\mathrm{LS}_{T} & =-0.2361 \mathrm{MD}+\mathrm{LS}_{U} \\
R^{2} & =0.9816
\end{aligned}
$$

where $\mathrm{LS}_{T}$ and $\mathrm{LS}_{U}$ are the linear shrinkage of treated and untreated expansive soil (\%), respectively.

4.7. Chemical and Mineralogical Analysis. The chemical interaction of the expansive soil mixtures with different MD additive ratios was determined by XRF and XRD analysis for 7 days of curing. The XRF results for UECS and TECS are shown in Table 3. From these results, it is found that the clay material presents a typical composition and is constituted mainly by silica and alumina and minor contents of $\mathrm{CaO}$, $\mathrm{MgO}, \mathrm{K}_{2} \mathrm{O}, \mathrm{TiO}_{2}, \mathrm{SO}_{3}$, and $\mathrm{MnO}$. A significant amount of iron oxide (11.94\%) is responsible for a darker coloring of the sintered samples. The loss on ignition (LOI) $(8.64 \%)$ is within the usual range for expansive clay material and is associated with volatile components and organic matter. The marble dust is formed basically by calcium oxide $(\mathrm{CaO})$ with minor contents of $\mathrm{SiO}_{2}, \mathrm{Al}_{2} \mathrm{O}_{3}, \mathrm{Fe}_{2} \mathrm{O}_{3}, \mathrm{MgO}, \mathrm{K}_{2} \mathrm{O}$, and $\mathrm{SO}_{3}$ indicating its carbonate nature. The loss on ignition (LOI) is higher than the clay material $(21.56 \%)$ and results from the decomposition of carbonates (calcite and dolomite). The high alkaline Earth oxide content, particularly $\mathrm{CaO}$, present in the MD will act as a fluxing agent during the sintering process. Also, it is found that $\mathrm{CaO}$ and $\mathrm{Fe}_{2} \mathrm{O}_{3}$ increased; $\mathrm{SiO}_{2}, \mathrm{Al}_{2} \mathrm{O}_{3}, \mathrm{Na}_{2} \mathrm{O}$, and $\mathrm{K}_{2} \mathrm{O}$ decreased with the increase in $\mathrm{MD}$ ratio. Although marble dust is reported as a chemically inert material [48], the alteration in the atomic percentage of $\mathrm{CaO}, \mathrm{Al}_{2} \mathrm{O}_{3}$, and $\mathrm{SiO}_{2}$ of the soil with an increase in marble confirms the possible ionic reactions. Jain et al. [41] indicated that the reaction between the ionic elements could be the reason behind the decrement in the $\mathrm{Si}$ and $\mathrm{Al}$ in the soilmarble dust with curing periods. The $\mathrm{Si}$ and $\mathrm{Al}$ from the soil and the $\mathrm{Ca}$ from the marble dust react in the presence of water to form cementitious compounds, which is an important factor for enhancing the strength behavior and for reducing the swelling percentage of the soil.

The XRD analyses of soil-marble dust mixes at the curing period of 7 days are compared with the mineralogical analyses of the parent materials (soil and marble dust) to examine the formation and variation in mineral peaks. As shown in Figure 16, the parent soil is predominated with montmorillonite and quartz whereas the marble dust is 


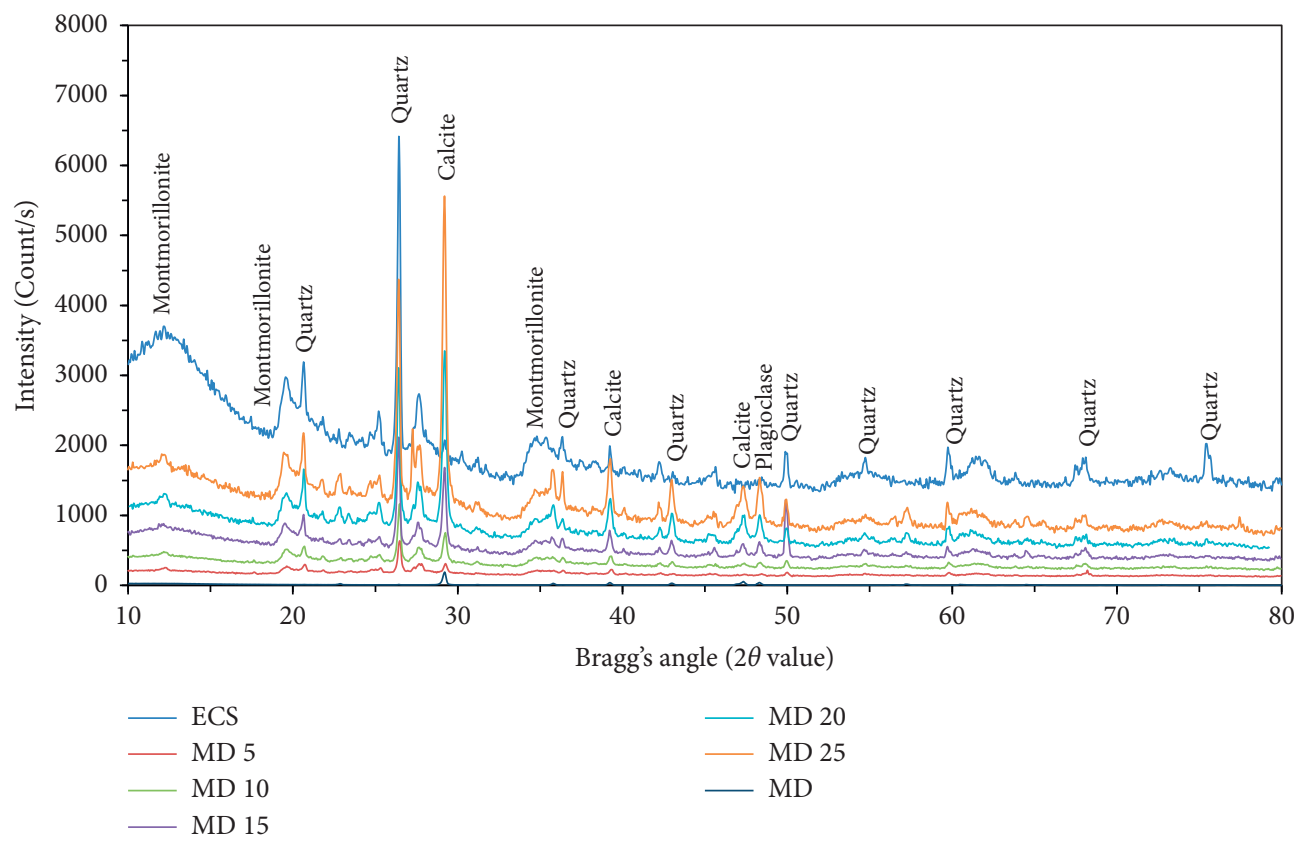

FIGURE 16: XRD analyses of MD, raw soil, and raw soil-MD mixes.

predominated with calcite. The calcite content of the soil mixtures increased with the increased replacement ratio of MD. This increment is related to the chemical composition of the marble dust, indicating the formation of a compacted soil matrix, and thereby, resulting in an optimum increase in the strength and a decrease in the swelling percentage. The crystalline phases identified are in agreement with the results observed by XRF as shown in Table 3. Similar behavior was also reported in the literature $[7,41]$.

In Table 3, MD is the marble dust, MD0 is the untreated expansive soil, MD5 is the treated expansive soil with $5 \%$ $\mathrm{MD}, \mathrm{MD} 10$ is the treated expansive soil with $10 \% \mathrm{MD}$, MD15 is the treated expansive soil with 15\% MD, MD20 is the treated expansive soil with $20 \% \mathrm{MD}$, and MD25 is the treated expansive soil with $25 \% \mathrm{MD}$.

\section{Conclusions}

The following conclusions can be drawn from the experimental results on the stabilization of expansive soil with marble dust:

(1) From the point of view of waste management, environmental conservation, and the economy, it is recommended that MD be used for stabilization of expansive soil with a substantial save in the cost of construction.

(2) Substantial decreases in Atterberg's limit, LL, PL, and PI were observed. The liquid limit decreases from $42.12 \%$ to $29.5 \%$, the plastic limit decreases from $25 \%$ to $18.8 \%$, and the plasticity index decreases from $17.12 \%$ to $10.7 \%$ with increasing the amount of MD up to $25 \%$. The rate of decrease is more up to $15 \%$, and after that, the rate of decrease is low.

(3) The classification of expansive soil changes from medium expansive soil to low expansive soil when stabilized with $25 \%$ MD.

(4) The maximum dry density (MDD) and optimum moisture content (OMC) of expansive soil increase and decrease with increasing percentages of $\mathrm{MD}$, respectively. MDD increases from $18.72 \mathrm{kN} / \mathrm{m}^{3}$ to $20.2 \mathrm{kN} / \mathrm{m}^{3}$ and the corresponding OMC decreases from $13.1 \%$ to $11.2 \%$ with increasing the amount of $\mathrm{MD}$ up to $25 \%$, and these variations are linear.

(5) The UCS increases from $417 \mathrm{kN} / \mathrm{m}^{2}$ to $600 \mathrm{kN} / \mathrm{m}^{2}$, i.e., improved by $47.48 \%$ at the addition of $25 \% \mathrm{MD}$ to the expansive soil for 7 days of curing periods. Also, the rate of increase is more up to $20 \% \mathrm{MD}$; after that, the rate is low. On the other hand, failure strain indicates a decreasing trend with the increment of MD content.

(6) The soaked CBR of expansive soil goes on increasing with an increase in the percentage of addition of MD. The soaked CBR increases from $6.19 \%$ to $12.9 \%$ when MD is increased up to $25 \%$. There is a $108 \%$ increase in soaked CBR value as compared to untreated soil when $25 \%$ MD was added.

(7) Detailed microanalyses (XRD and XRF) confirmed that various factors (i.e., the alteration of the parent minerals and the formation of new minerals) affect the strength and swell behavior of soil-marble dust mixes, where the calcite content of the soil mixtures increased with the increased replacement ratio of 
MD. This increment is related to the chemical composition of the marble dust, indicating the formation of a compacted soil matrix, and thereby, resulting in an optimum increase in the strength and a decrease in the swelling percentage.

\section{Data Availability}

The data used to support the findings of this study are available from the corresponding author upon request.

\section{Conflicts of Interest}

The authors declare that they have no conflicts of interest.

\section{Acknowledgments}

The authors would like to thank the staff of the Geotechnical Laboratory, Mining Engineering Department, Faculty of Engineering, Qena, Al-Azhar University, for helping in the laboratory testing work.

\section{References}

[1] D. E. Jones and W. G. Holtz, "Expansive soils-the hidden disaster," Civil Engineering, vol. 43, no. 8, pp. 49-51, 1973.

[2] M. Y. Fattah, N. M. Salim, and E. J. Irshayyid, "Swelling behavior of unsaturated expansive soil," Transportation Infrastructure Geotechnology, vol. 8, no. 1, pp. 37-58, 2021.

[3] B. Soomro, S. A. Mangi, R. A. Bajkani, and A. Q. Junejo, "Recycling of ceramic tiles and marble powder waste as partial substitution in concrete," Neutron, vol. 20, no. 2, pp. 128-137, 2021, p.

[4] D. M. Sadek, M. M. El-Attar, and H. A. Ali, "Reusing of marble and granite powders in self-compacting concrete for sustainable development," Journal of Cleaner Production, vol. 121, pp. 19-32, 2016.

[5] R. A. Hamza, S. El-Haggar, and S. Khedr, "Marble and granite waste: characterization and utilization in concrete bricks," International Journal of Bioscience, Biochemistry and Bioinformatics, vol. 1, no. 4, pp. 286-291, 2011.

[6] H. Binici, H. Kaplan, and S. Yilmaz, "Influence of marble and limestone dust as additives on some mechanical properties of concrete," Scientific Research and Essays, vol. 2, no. 9, pp. 372-379, 2007.

[7] N. Ural, C. Karakurt, and A. T. Cömert, "Influence of marble wastes on soil improvement and concrete production," Journal of Material Cycles and Waste Management, vol. 16, no. 3, pp. 500-508, 2014.

[8] A. K. Sabat and S. Pati, "A review of literature on stabilization of expansive soil using solid wastes," Electronic Journal of Geotechnical Engineering, vol. 19, 2014.

[9] T. G. Soosan, B. T. Jose, and B. M. Abraham, "Use of crusher dust in embankment and highway construction," in Proceedings of Indian Geo-Technical Conference, pp. 274-277, Indore, India, December 2001.

[10] O. Sivrikaya, K. R. Kiyıldı, and Z. Karaca, "Recycling waste from natural stone processing plants to stabilise clayey soil," Environmental Earth Sciences, vol. 71, no. 10, pp. 4397-4407, 2014.

[11] A. S. Eltwati, F. Tarhuni, and A. Elkaseh, "Engineering properties of clayey soil stabilized with waste granite dust," Journal of Critical Reviews, vol. 7, no. 16, pp. 794-802, 2020.
[12] A. Arulrajah, J. Piratheepan, M. M. Disfani, and M. W. Bo, "Geotechnical and geoenvironmental properties of recycled construction and demolition materials in pavement subbase applications," Journal of Materials in Civil Engineering, vol. 25, no. 8, pp. 1077-1088, 2013.

[13] A. F. Cabalar, M. D. Abdulnafaa, and Z. Karabash, "Influences of various construction and demolition materials on the behavior of a clay," Environmental Earth Sciences, vol. 75, no. 9, p. 841, 2016.

[14] M. A. Rahman, M. A. Imteaz, A. Arulrajah, J. Piratheepan, and M. M. Disfani, "Recycled construction and demolition materials in permeable pavement systems: geotechnical and hydraulic characteristics," Journal of Cleaner Production, vol. 90, pp. 183-194, 2015.

[15] A. Arulrajah, M. M. Disfani, S. Horpibulsuk, C. Suksiripattanapong, and N. Prongmanee, "Physical properties and shear strength responses of recycled construction and demolition materials in unbound pavement base/subbase applications," Construction and Building Materials, vol. 58, pp. 245-257, 2014.

[16] T. G. Soosan, A. Sridharan, B. T. Jose, and B. M. Abraham, "Utilization of quarry dust to improve the geotechnical properties of soils in highway construction," Geotechnical Testing Journal, vol. 28, no. 3, pp. 391-400, 2005.

[17] H. Bansal and G. S. Sidhu, "Influence of waste marble powder on characteristics of clayey soil," International Journal of Science and Research, vol. 5, no. 8, pp. 78-82, 2016.

[18] S. Chandra, P. Kumar, and B. A. Feyissa, "Use of marble dust in road construction," Road Materials and Pavement Design, vol. 3, no. 3, pp. 317-330, 2002.

[19] A. S. Bshara, E. Y. Bind, and P. K. Sinha, "Effect of stone dust on geotechnical properties of poor soil," International Journal of Civil Engineering and Technology, vol. 5, no. 4, pp. 37-47, 2014.

[20] R. Ali, H. Khan, and A. A. Shah, "Expansive soil stabilization using marble dust and bagasse ash," International Journal of Science and Research, vol. 3, pp. 2812-2816, 2014.

[21] K. A. Palaniappan and V. K. Stalin, "Utility effect of solid wastes in problematic soils," International Journal of Engineering Research and Industrial Applications, vol. 2, no. 1, pp. 313-321, 2009.

[22] A. F. Cabalar, D. I. Hassan, and M. D. Abdulnafaa, "Use of waste ceramic tiles for road pavement subgrade," Road Materials and Pavement Design, vol. 18, no. 4, pp. 882-896, 2017.

[23] A. Mohammadinia, A. Arulrajah, J. Sanjayan, M. M. Disfani, M. W. Bo, and S. Darmawan, "Laboratory evaluation of the use of cement-treated construction and demolition materials in pavement base and subbase applications," Journal of Materials in Civil Engineering, vol. 27, no. 6, Article ID 04014186, 2015.

[24] H. H. Ibrahim, Y. M. Alshkane, Y. I. Mawlood, K. M. G. Noori, and A. M. Hasan, "Improving the geotechnical properties of high expansive clay using limestone powder," Innovative Infrastructure Solutions, vol. 5, no. 3, pp. 1-11, 2020.

[25] T. H. Selim and A. I. Kandil, "Characteristics of the marble industry in Egypt: structure, conduct, and performance," International Business and Economics Research Journal, vol. 5, no. 3, pp. 25-34, 2006.

[26] A. T. Sroor, S. M. Darwish, S. M. El-Bahi, and M. G. A. Karim, "Radiological hazards for marble and granite used at Shak El Thouban industrial zone in Egypt," Journal of Environmental Protection, vol. 4, no. 12, pp. 41-48, 2013. 
[27] A. S. Eltwati and F. Saleh, "Improvement of subgrade soils by using marble dust-(Libya, case study)," The International Journal of Engineering and Information Technology, vol. 6, no. 2, pp. 40-44, 2020.

[28] V. Agrawal and M. Gupta, "Expansive soils stabilization using marble dust," International Journal of earth sciences and engineering, vol. 4, no. 6, pp. 59-62, 2011.

[29] R. P. Arora, N. K. Ameta, K. K. Samar, and K. L. Samdani, "Improvement of engineering characteristics of the locally available soil mass by use of marble dust," International Inventive Multidisciplinary Journal, vol. 2, no. 4, pp. 8-15, 2014.

[30] M. M. E. Zumrawi and E. A. A. Abdalla, "Stabilization of expansive soil using marble waste powder," in Proceedings of the Second conference of civil engineering in Sudan, pp. 266271, Khortoum, Sudan, December 2018.

[31] Ş. Öncü and H. Bilsel, "Utilization of waste marble to enhance volume change and strength characteristics of sand-stabilized expansive soil," Environmental Earth Sciences, vol. 77, no. 12, pp. 1-13, 2018.

[32] F. E. Jalal, k. Shahzada, S. Saeed, I. Ahmed, and K. Ullah, "Stabilization of medium expansive soils in Pakistan using marble industrial waste and bagasse ash," International Journal of Earth Sciences and Engineering, vol. 10, no. 4, pp. 885-891, 2017.

[33] O. Başer, "Stabilization of expansive soils using waste marble dust," Master's thesis, Civil Engineering Department, Middle East Technical University, Ankara, Turkey, 2009.

[34] R. S. Abdulla and N. N. Majeed, "Some physical properties treatment of expansive soil using marble waste powder," International Journal of Engineering Research and Technology, vol. 3, no. 1, pp. 591-600, 2014.

[35] S. N. Bhavsar, H. B. Joshi, P. K. Shrof, and P. J. Ankit, "Impact of marble powder on engineering properties of black cotton soil," International journal for scientific research and development, vol. 2, pp. 2321-2613, 2014.

[36] I. Zorluer and M. Usta, "Stabilization of soils by waste marble dust," in Proceedings of the fourth national marble symposium (in Turkish), pp. 305-311, Afyon, Turkey, December 2003.

[37] P. S. Singh and R. K. Yadav, "Effect of marble dust on index properties of black cotton soil," International Journal of Engineering Research and Science and Technology, vol. 3, no. 3, pp. 158-163, 2014.

[38] A. K. Sabat and R. P. Nanda, "Effect of marble dust on strength and durability of rice husk ash stabilized expansive soil," International Journal of Civil and Structural Engineering, vol. 1, no. 4, pp. 939-948, 2011.

[39] A. Saygili, "Use of waste marble dust for stabilization of clayey soil," Materials Science, vol. 21, no. 4, pp. 601-606, 2015, p.

[40] O. Sivrikaya, F. Uysal, A. Yorulmaz, and K. Aydin, "The Efficiency of waste marble powder in the stabilization of finegrained soils in terms of volume changes," Arabian Journal for Science and Engineering, vol. 45, no. 10, pp. 8561-8576, 2020.

[41] A. K. Jain, A. K. Jha, and Shivanshi, "Geotechnical behaviour and micro-analyses of expansive soil amended with marble dust," Soils and Foundations, vol. 60, no. 4, pp. 737-751, 2020.

[42] W. G. Holtz and H. J. Gibbs, "Engineering properties of expansive clays," Transactions of ASCE, vol. 121, pp. 641-663, 1953.

[43] F. H. Chen, Foundations on Expansive Soils, Elsevier, Amsterdam, Netherlands, 1975.

[44] Bureau of Indian Standards, Indian Standard Classification and Identification of Soils for General Engineering Purposes, Reaffirmed 1987, New Delhi, India, 1498.
[45] C. O. Okagbue and T. U. S. Onyeobi, "Potential of marble dust to stabilise red tropical soils for road construction," Engineering Geology, vol. 53, no. 3-4, pp. 371-380, 1999.

[46] R. Choksi, C. Mishra, and N. Patel, "Pursuance of waste marble powder to improve soil stabilization," International Research Journal Engineering Technology (IRJET), vol. 5, no. 5, pp. 1695-1698, 2018.

[47] A. K. Sabat and B. Bose, "Improvement in geotechnical properties of an expansive soil using fly ash-quarry dust mixes," Electronic Journal of Geotechnical Engineering, vol. 18, pp. 3487-3500, 2013.

[48] A. Gurbuz, "Marble powder to stabilise clayey soils in subbases for road construction," Road Materials and Pavement Design, vol. 16, pp. 481-492, 2005. 